\title{
Notes on the vocalizations of Chestnut-crowned Laughingthrush (Trochalopteron erythrocephalum) and allies
}

Peter Boesman

In the following we briefly analyze and compare voice of Chestnut-crowned Laughingthrush (Trochalopteron erythrocephalum) and its allies. We also try to quantify the extent of any vocal differences using the criteria proposed by Tobias et al. (2010), as a support for taxonomic review. We have made use of sound recordings available on-line from Xeno Canto (XC) and Macaulay Library (ML).

HBW recognizes the following closely-related species: Chestnut-crowned Laughingthrush (Trochalopteron erythrocephalum), Assam Laughingthrush (Trochalopteron chrysopterum), Silver-eared Laughingthrush (Trochalopteron melanostigma), Golden-winged Laughingthrush (Trochalopteron ngoclinhense) and Malayan Laughingthrush (Trochalopteron peninsulae) (del Hoyo et al. 2016). We here compare voice of these five species:

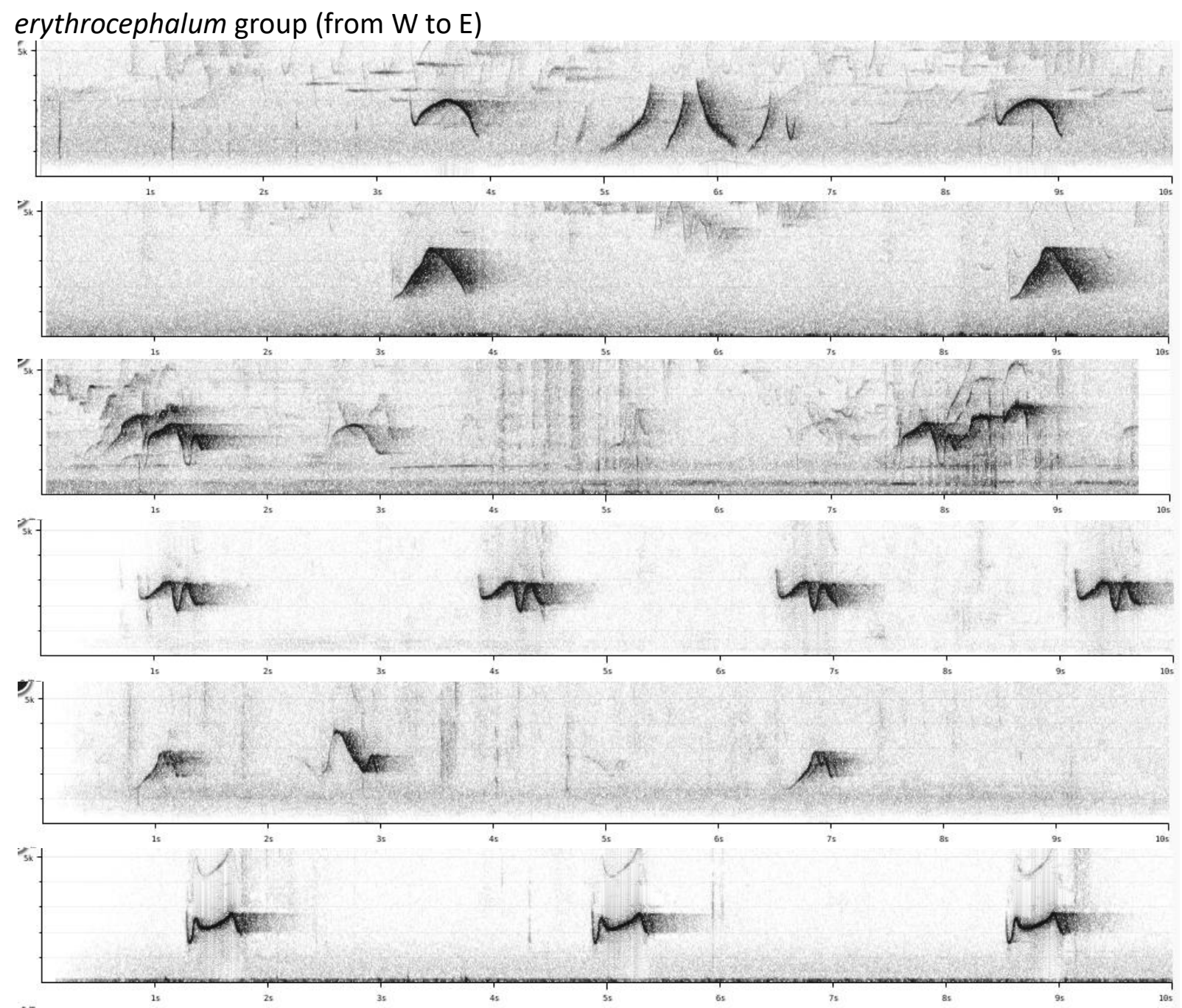




\section{HANDBOOK OF THE Allue}

\section{ORNITHOLOGICAL NOTES}

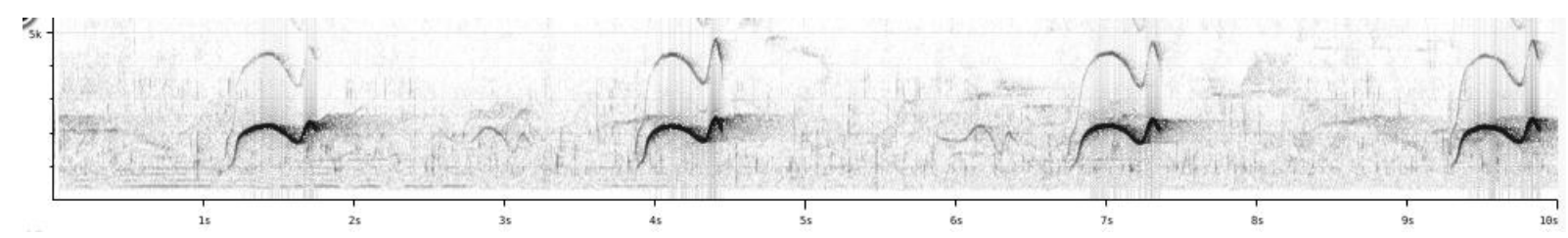

chrysopterum group

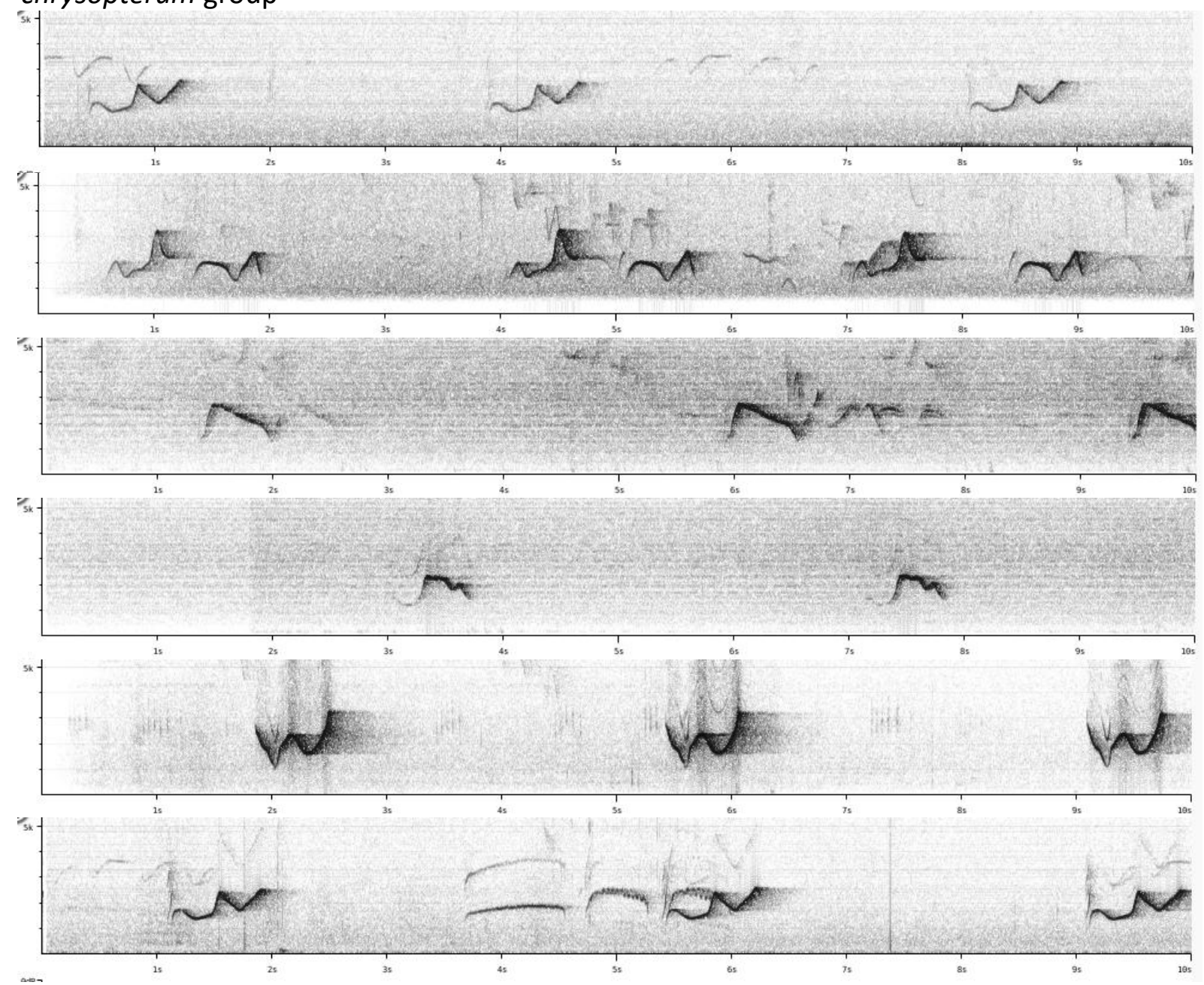

Whistles said to be generally lower-pitched and mellower than those of $T$. erythrocephalum (HBW Alive, Collar et al. 2016). From the above examples: 5 out of 7 (71\%) of previous groups reach $3 \mathrm{kHz}$ versus 2 out of $5(40 \%)$ of present group. The statement is thus correct on average, but there is considerable overlap. Furthermore, notes are on average also slightly longer in duration. Last sonogram is probably duet, with 3 nasal whistles given by female. 
HANDBOOK OF THE

BIRDS PF, THE WORLD

ORNITHOLOGICAL NOTES

melanostigma group
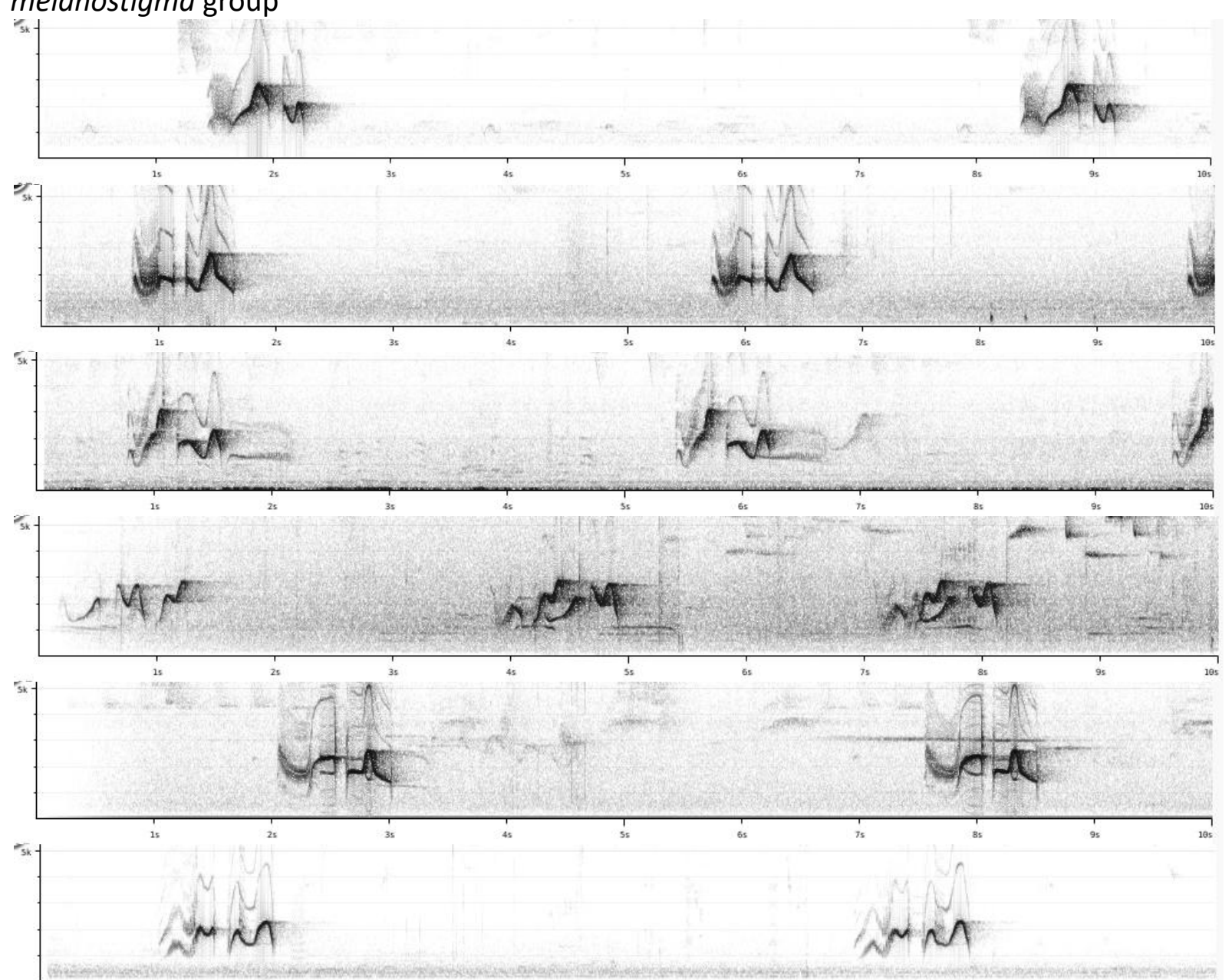

Unlike the two previous groups, song phrase consists typically of 2 (or 3 ) notes, thus resulting also in a longer duration of a song phrase. First whistle may start with a slightly burry tone quality.

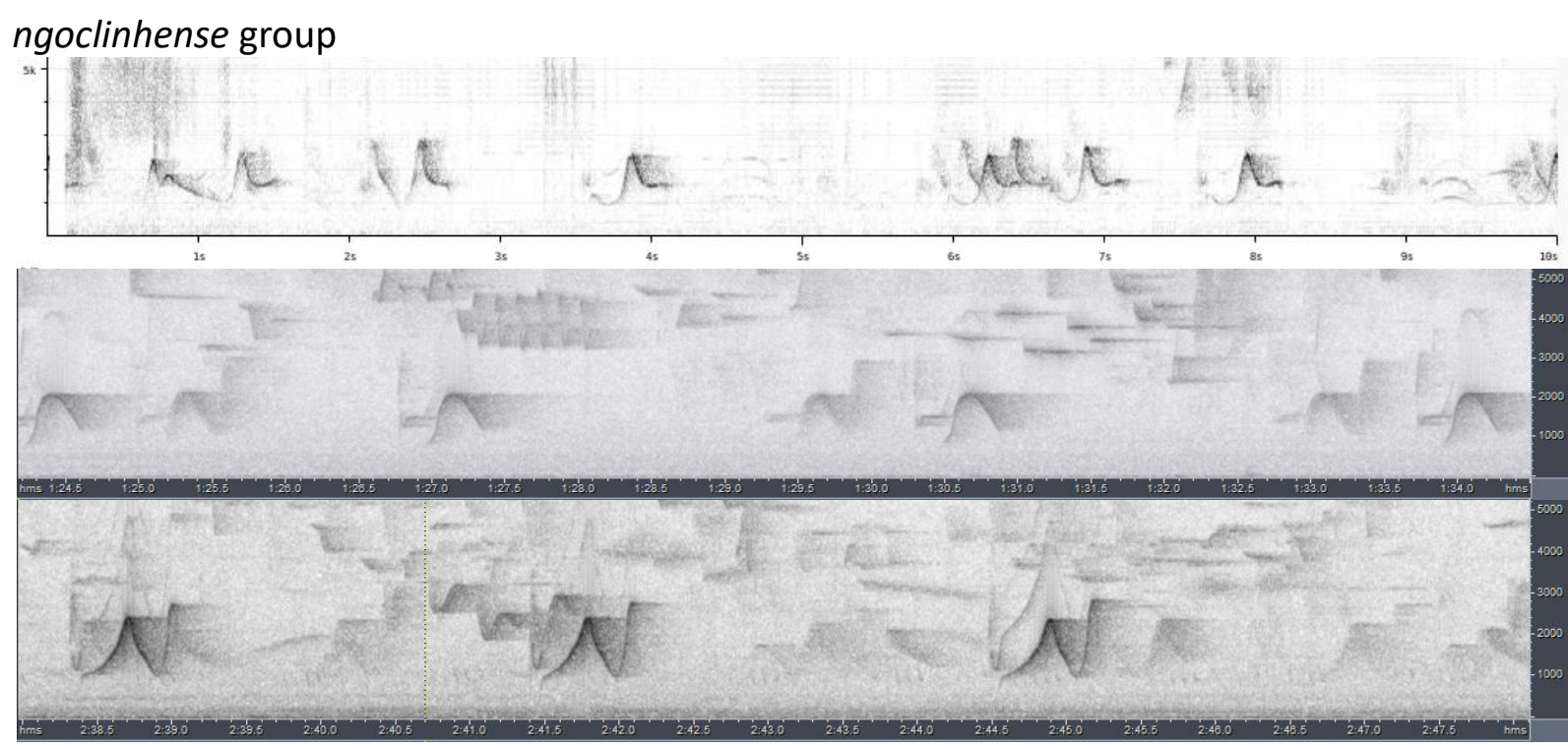




\section{HANDBOOK OF THE Aluve}

\section{ORNITHOLOGICAL NOTES}

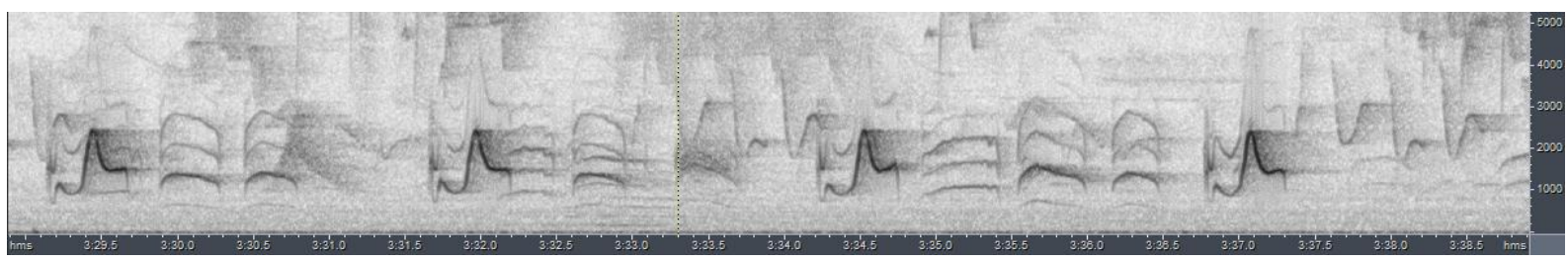

Song is a single, overslurred whistle. Last sonogram probably is a duet, with 3 nasal whistles by female. Most similar to chrysopterum group (single note, same pitch). Probably not safely told apart, although on average note shape simpler and shorter.

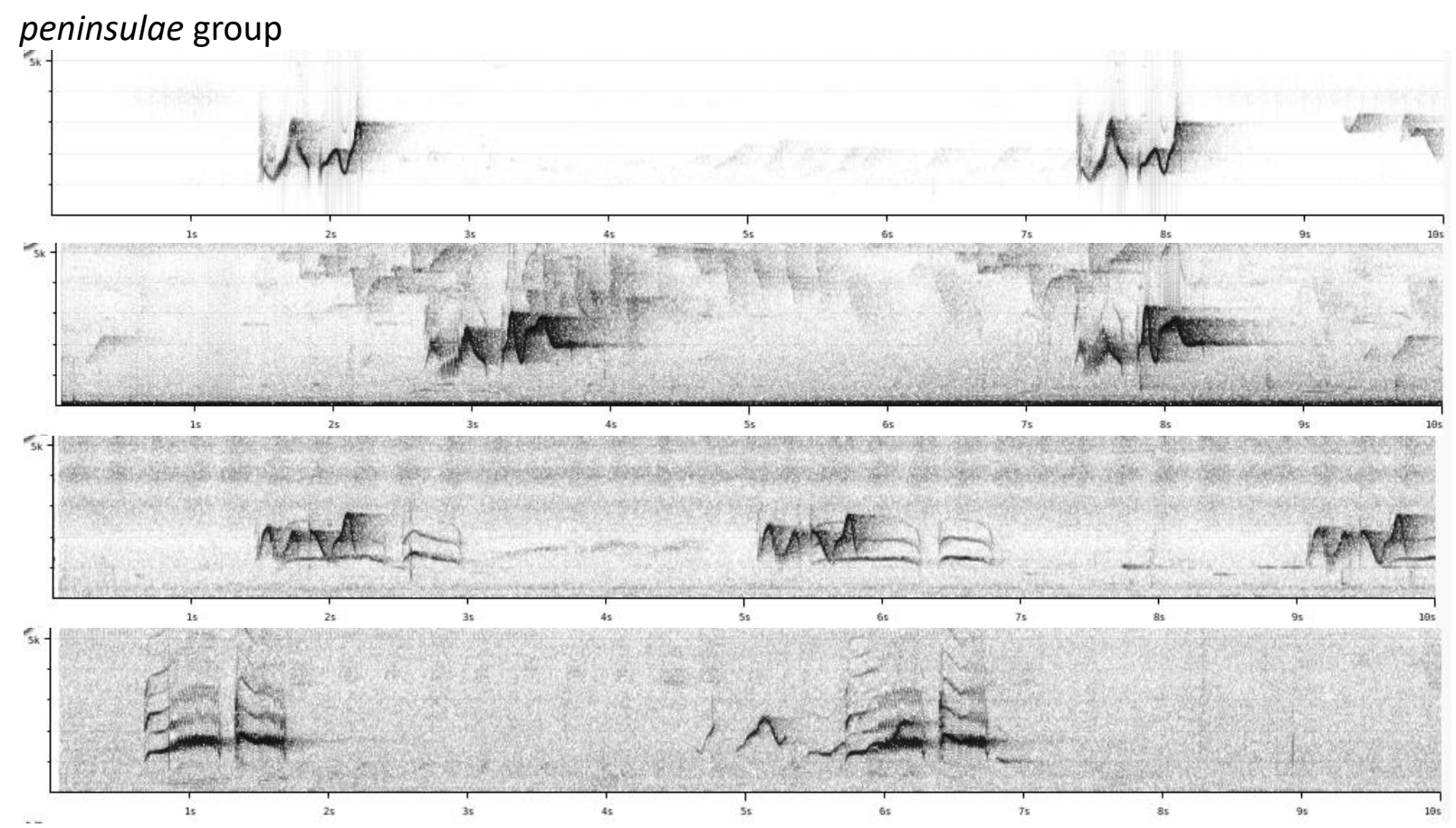

Voice quite similar to melanostigma group, sharing the double note song, burry quality to some whistles etc. Present group seems to duet often, the second bird giving two burry whistles at about constant pitch (but note that 2 out of 5 examples above of melanostigma group seem to show similar duetting notes in the background). These two groups can probably not safely told apart.

Differences in voice among the five groups are thus rather subtle, the main distinguishing feature being number of notes in a song phrase, duration of a song phrase, and note length.

Scoring vocal differences results in a 10 pair-wise comparisons. 

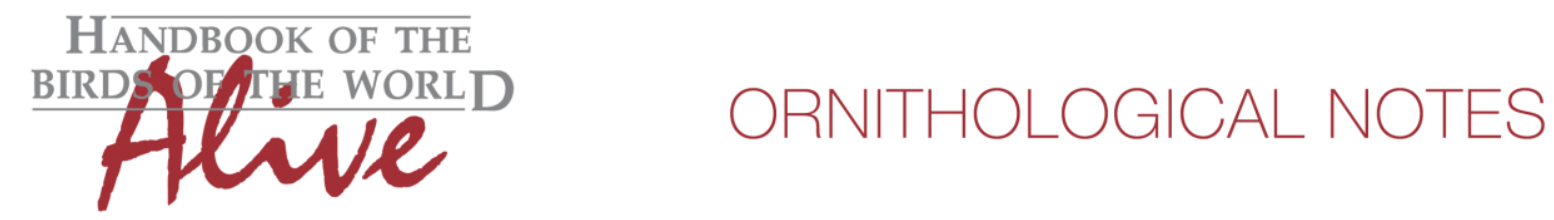

Chestnut-crowned Laughingthrush (T. erythrocephalum) vs Assam Laughingthrush (T. chrysopterum)

$\rightarrow$ score 1 (slightly different pitch)

Chestnut-crowned Laughingthrush (T. erythrocephalum) vs Silver-eared Laughingthrush (T. melanostigma)

-> score 3-4 (\# of notes and/or duration)

Chestnut-crowned Laughingthrush (T. erythrocephalum) vs Golden-winged Laughingthrush (T. ngoclinhense)

-> score 2-3 (slightly different pitch, shorter notes)

Chestnut-crowned Laughingthrush (T. erythrocephalum) vs Malayan Laughingthrush (T. peninsulae)

-> score 3-4 (\# of notes and/or duration)

Assam Laughingthrush (T. chrysopterum) vs Silver-eared Laughingthrush (T. melanostigma)

-> score 3-4 (\# of notes and/or duration)

Assam Laughingthrush (T. chrysopterum) vs Golden-winged Laughingthrush (T. ngoclinhense)

-> score 2 (shorter notes)

Assam Laughingthrush (T. chrysopterum) vs Malayan Laughingthrush (T. peninsulae)

-> score 3 (\# of notes)

Silver-eared Laughingthrush (T. melanostigma) vs Golden-winged Laughingthrush (T. ngoclinhense)

$\rightarrow$ score 4 (\# of notes and duration)

Silver-eared Laughingthrush (T. melanostigma) vs Malayan Laughingthrush (T. peninsulae)

-> score 0

Golden-winged Laughingthrush (T. ngoclinhense) vs Malayan Laughingthrush (T. peninsulae)

-> score 4 (\# of notes and duration)

A more in depth vocal analysis may reveal additional differences. Female vocalization seems also worth checking.

This note was finalized on 13th April 2016, using sound recordings available on-line at that moment. We would like to thank in particular the many sound recordists who placed their recordings for this species on XC and ML.

\section{References}

Collar, N. \& Robson, C. (2016). Assam Laughingthrush (Trochalopteron chrysopterum). In: del Hoyo, J., Elliott, A., Sargatal, J., Christie, D.A. \& de Juana, E. (eds.). Handbook of the Birds of the World Alive. Lynx Edicions, Barcelona. (retrieved from http://www.hbw.com/node/59641 on 13 April 2016).

del Hoyo, J., Elliott, A., Sargatal, J., Christie, D.A. \& de Juana, E. (eds.)(2016). Handbook of the Birds of the World Alive. Lynx Edicions, Barcelona.

Tobias, J.A., Seddon, N., Spottiswoode, C.N., Pilgrim, J.D., Fishpool, L.D.C. \& Collar, N.J. (2010). Quantitative criteria for species delimitation. Ibis 152(4): 724-746.

\section{Recommended citation}

Boesman, P. (2016). Notes on the vocalizations of Ornate Antwren (Myrmotherula ornata). HBW Alive Ornithological Note 45. In: Handbook of the Birds of the World Alive. Lynx Edicions, Barcelona. (retrieved from http://www.hbw.com/node/931753 on 25 April 2016). 
HANDBOOK OF THE

BIRD PIP TUE WORLD

ORNITHOLOGICAL NOTES

Boesman, P. (2016). Notes on the vocalizations of Chestnut-crowned Laughingthrush (Trochalopteron erythrocephalum) and allies. HBW Alive Ornithological Note 276. In: Handbook of the Birds of the World Alive. Lynx Edicions, Barcelona. (retrieved from http://www.hbw.com/node/1251717 on 8 October 2016).

6 